\title{
THE RESEARCH PROJECT "EARTHEN ARCHITECTURE IN THE IBERIAN PENINSULA: STUDY OF NATURAL, SOCIAL AND ANTHROPIC RISKS AND STRATEGIES TO IMPROVE RESILIENCE (RISK-TERRA)”. OBJECTIVES AND FIRST METHODOLOGY.
}

\author{
C. Mileto ${ }^{1, *}$, F. Vegas ${ }^{1}$, V. Cristini ${ }^{1}$, L. García-Soriano ${ }^{1}$ \\ ${ }^{1}$ Research Centre PEGASO, Universitat Politècnica de València, Valencia, Spain - (cami2, fvegas, vacri)@ cpa.upv.es, \\ ligarso@upv.es
}

Commission II - WG II/8

KEY WORDS: Earthen architecture, Natural risks, Social risks, Conservation, Preventive conservation, Protection

\begin{abstract}
:
The Iberian Peninsula possesses extensive earthen monumental and vernacular architectural heritage. The extension of the territory and its heterogeneous geography and climate, variety of available materials, and cultural diversity are the main factors which have brought about the great wealth of both the architecture, urban and rural settings, and the constructive techniques mainly using earth (rammed earth, adobe, half-timber, cob and its variants). However, despite being an essential part of the Iberian culture, this heritage has been greatly abandoned due to changes in ways of life, the depopulation of rural areas, the lack of social recognition, etc. The research project "Risk-Terra - Earthen architecture in the Iberian Peninsula: study of natural, social and anthropic risks and strategies to improve resilience" (ref. RTI2018-095302-B-I00), funded by the Spanish Ministry of Science, Innovation and University (20192021) aims to provide a scientific study of natural hazards (floods, landslides, earthquakes, winds, rise of temperatures), social hazards (abandonment, loss of social reputation, demographic pressure, tourism development...) and anthropic hazards (carelessness and negligence, lack of protection and maintenance...), as well as deterioration mechanisms (erosion, loss of materials/parts, collapse...) and transformation dynamics (replacement, use of incompatible techniques and materials...), to which the earthen architecture of the Iberian Peninsula is currently subject.. This paper presents the general and specific objectives and the methodology to be used in the project.
\end{abstract}

\section{INTRODUCTION}

Earthen architecture, linked to the geography and natural resources of the territory (Mileto, 2019), culture and local economy, is a heritage of great importance and interest in the Iberian Peninsula (Mileto, 2017). This heritage covers not only domestic buildings -in rural settings and different-sized urban nuclei - but also monumental complexes and archaeological sites. Earthen architecture, born from local materials (earth, lime, gypsum, stone, etc.) (Figure 1), has adapted over the centuries to the climates and environments of individual settings, optimising resources and showing mechanisms for improving resilience thanks to constructive knowledge in the face of natural disasters (Gómez, 2019).

These values and teachings can be a valuable source of learning for society at present (Mileto, 2018). In addition, monumental and vernacular earthen architecture is currently subject to major natural, social and anthropic hazards (Figure 2), and especially situations of risk resulting from the different hazards and mechanisms of action, degradation (Figure 3 ) and transformation (Figure 4). In fact, this research has focused on earthen architecture precisely because of its prevalence in the territory and cultural wealth. This architecture, seemingly fragile in relation to atmospheric agents, is currently maligned given its connotations of poverty. Furthermore, the prevention of natural risks and phenomena resulting from climate change are currently a priority in many fields, including cultural heritage (ICOMOS, 2010; Andreatta, 2017).
After identifying the hazards for cultural heritage and the exposure probability, it is necessary to establish its vulnerability (defined by the UNESCO "the conditions determined by physical, social, economic, and environmental factors or processes, which increase the susceptibility of a community to the impact of hazards, including exposure) (UNESCO, 2010).

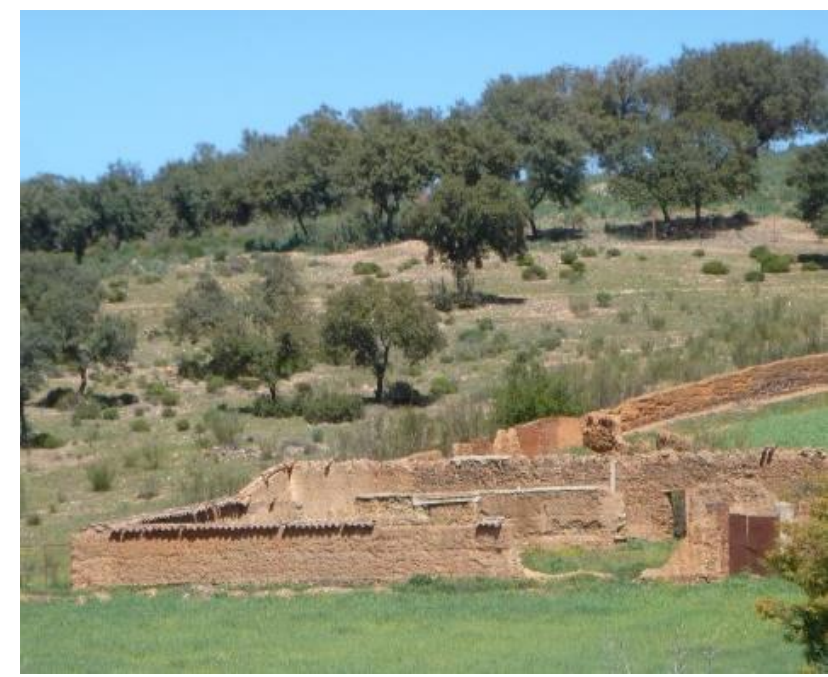

Figure 1. Relationship between the matter from the landscape and the rammed earth walls (Navalpino, Ciudad Real)

\footnotetext{
* Corresponding author
} 
Finally, the levels of risk allow to design measures for the prevention and mitigation of effects through interventions reinforcing and increasing resilience factors (AAVV, 2014).

The research project "Risk-Terra - Earthen architecture in the Iberian Peninsula: study of natural, social and anthropic risks and strategies to improve resilience" (ref. RTI2018-095302B-I00), funded by the Spanish Ministry of Science, Innovation and University (2019-2021) is placed in this context.

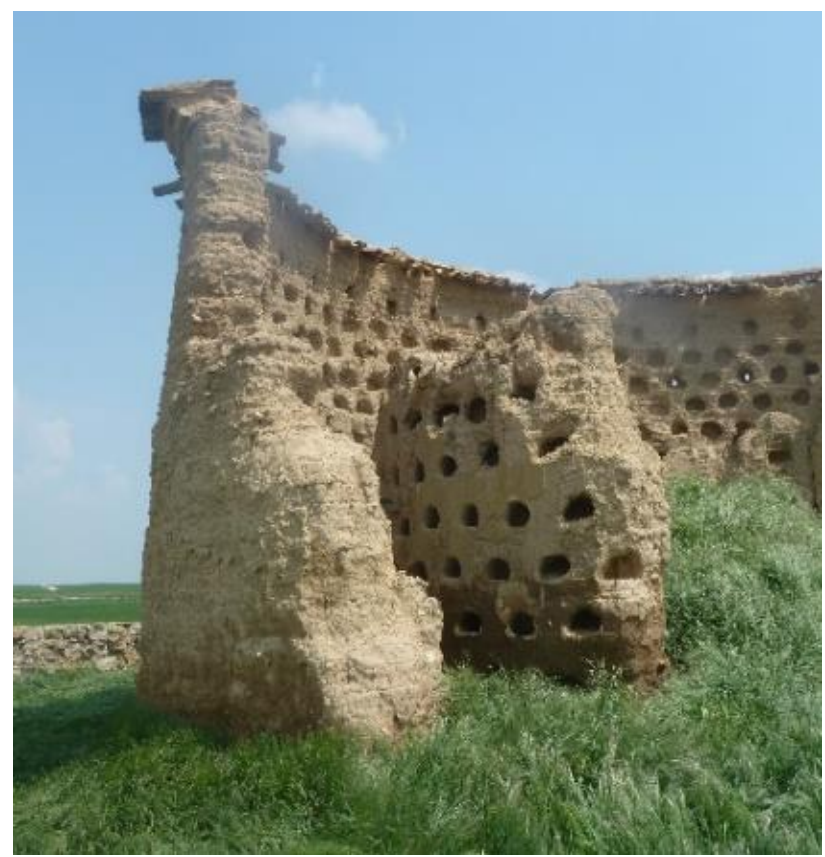

Figure 2. Abandonment by functional obsolescence of earthen architecture (dovecote in Castilla y León)

\section{OBJECTIVES OF THE REASEARCH}

\subsection{General objectives}

Three general objectives can therefore be proposed for the RISK-Terra research project:

1. To contribute to the valorisation of earthen architecture in the Iberian Peninsula as an architecture valid for contemporary society and lifestyle. In order to attain this general objective it is essential to clearly state its cultural, technical, bioclimatic and environmental values, as well as its resilience when faced with natural, social and anthropic hazards. This objective aims to contribute to the development of current society favouring the construction of these values and represents an indirect goal which will be achieved through the compilation and dissemination of information.

2. To contribute to the prevention, planning and prioritizing against natural, social and anthropic risks to earthen architecture and society in the Iberian Peninsula. To this end the natural, social and anthropic hazards will be identified, along with the levels of risk and vulnerability of this architecture. In addition objective homogeneous levels of risk will be established in order to plan and prioritize actions in built heritage directed at protecting, intervening and investing depending on the different levels of urgency and emergency.
3. To encourage compatible interventions in conservation, restoration and rehabilitation geared towards increasing the resilience of the built earthen heritage in the Iberian Peninsula. Once the heritage importance of earthen architecture is recognised and the hazards, vulnerabilities and risks affecting it have been identified, a path towards compatible interventions (in materials and techniques) must be provided allowing an increase in the resilience of this architecture through prevention and mitigation of the effects of natural, social and anthropic risks.

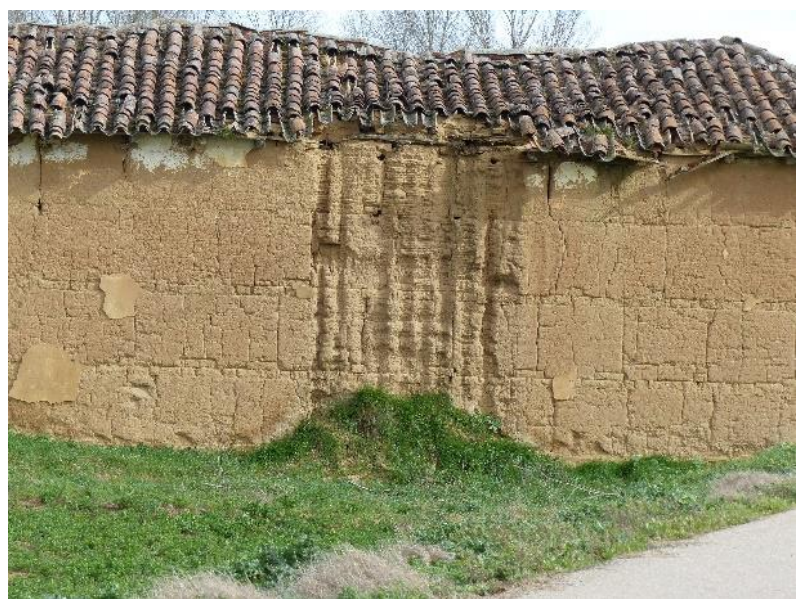

Figure 3. Washing of the wall caused by rain (Valderas, León)

\subsection{Specific objectives}

The following specific objectives are proposed in addition to the three general objectives:

1. Organisation and systematisation of the study of earthen architecture in the Iberian Peninsula. The architectural and archaeological earthen heritage, as well as the techniques and materials used to establish architectural, heritage and constructive families should be catalogued in a database and detailed mappings, as can be seen from previous studies and research.

2. Identification of natural, social and anthropic hazards and level of risk to earthen architecture in the Iberian Peninsula. In order to attain this objective all potential threats to earthen architecture in the Iberian Peninsula will be identified, and hazard and risk plans will be drawn up for the monumental, vernacular and archaeological earthen heritage, identifying the areas or regions most at risk.

3. Updating \& application to case studies of a methodology for the analysis and assessment of vulnerability of earthen architecture. This multidisciplinary methodology will cover the different aspects affecting the susceptibility of earthen architecture and its resilience to natural, social and anthropic hazards. Highlighting these aspects of monumental, vernacular and archaeological earthen heritage will be relevant for the design of future interventions.

4. Development of risk maps for earthen architecture in the Iberian Peninsula. The risk maps obtained can be a useful tool for the management, prevention and prioritizing of interventions for the protection, conservation and rehabilitation of this heritage. They can also be useful decision-making tools when investing public funds. 
5. Drawing up guidelines for the design of strategies for intervention and for increasing resilience. These guidelines will be drawn up based on the results of the research developed. The aim is to create a body of knowledge to establish an intervention strategy for prevention, conservation, restoration and rehabilitation defining the criteria and specific intervention techniques for improving the resilience of the monumental, vernacular and archaeological earthen heritage of the Iberian Peninsula.

6. Transmission of knowledge acquired and training for professionals and future professionals through various actions: conferences, websites, organising an exhibition and other related actions.

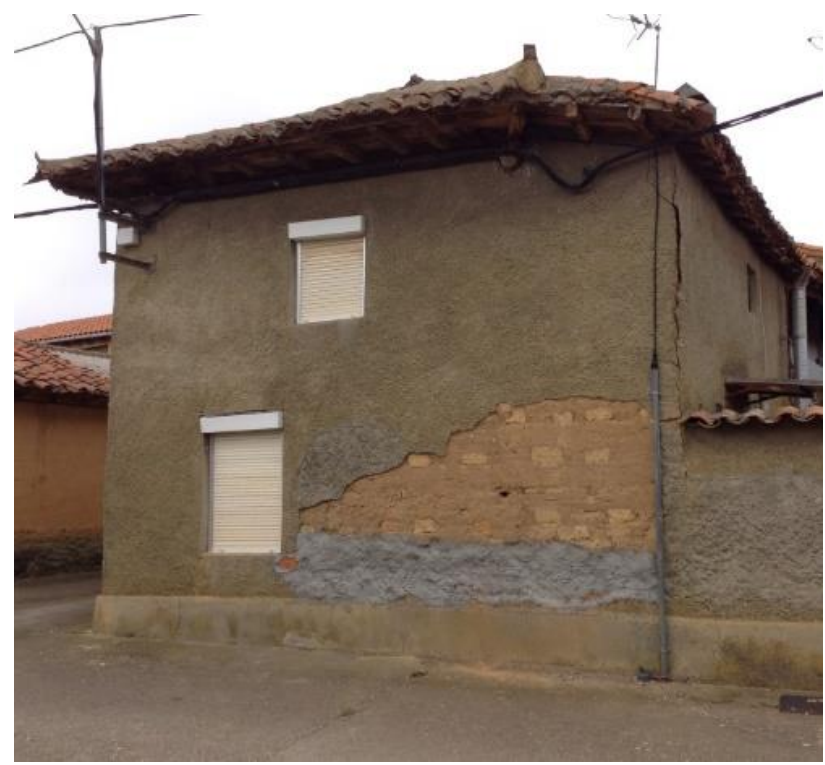

Figure 4. Transformation of an earthen house (Molezuela de la Carballeda, Zamora)

\section{RESEARCH METHODOLOGY}

The methodology proposed for this research will consist of phases for cataloguing, analysis and assessment, using qualitative and quantitative, heuristic, statistical and probabilistic methods with data from different sources (redrafting existing information, case studies and experimental studies) at different scales (territorial, regional and local, architectural and detail). In order to obtain sufficient data several tools are expected to be used: analysis of the bibliography and sources, interviews and surveys, fieldwork, development of a database, use of existing themed maps, direct study of architecture and construction, modelling and structural calculation, analysis and experimentation.

The research team is multi-disciplinary: the researchers are architects, structural experts, archaeologists, geologists and engineers. The researchers belong to differente Spanish and Portuguese universities: C. Mileto, F. Vegas. A. Guardiola, L. Basset, J. Torrijo, V. Cristini, L. García Soriano (all of theme from Universitat Politècnica de València), F. Vela (Universidad Politécnica de Madrid), A. González Serrano (Universida de Sevilla), J.M. López Osorio (Universidad de Málaga), V. La Spina (Universidad Politécnica de Cartagena), M. Correia (Escola Superior Gallaecia), Paulo Lourenço (University of Minho).

\subsection{Phase 1: study of earthen architecture in the iberian peninsula}

TASK 1.1: Collection and reworking of existing information already compiled in previous projects (RES-Tapia, SOS-Tierra) as well as published in articles, books, websites and multimedia resources on earthen architecture in the Iberian Peninsula. All the information existing on earthen architecture in monumental buildings, grouped and scattered traditional architecture and archaeological sites.

TASK 1.2: Identification of protected earthen assets using official databases: an important tool for identifying architectural and archaeological earthen assets protected in Spain is the Base de datos de Bienes Inmuebles del Ministerio de Educación, Cultura y Deporte (www.mecd.gob.es/bienes/). For Portugal there is also the database of the Inventário do Património Arquitectonico de la Direção Geral de Patrimonio Cultural (www.monumentos.pt). For non protected vernacular heritage, the database of the SOS-Tierra project (over 2,000 entries) will be used (https://sostierra.blogs.upv.es/).

TASK 1.3: Database for monumental, vernacular and archaeological sites in earthen architecture: all the data gathered will be used to create a database for earthen architecture in the Iberian Peninsula. This database will be based on those from previous projects, incorporating the assets identified in task 1.2 and will contain at least the following data for every entry: asset name, location (UTM coordinates), general photography, typology, morphology, constructive techniques, conservation status, interventions carried out, etc.

TASK 1.4: Mapping of typological and morphological characteristics: the database developed in task 1.3 will be used to produce an atlas of the different types of monumental earthen heritage (religious buildings, civil buildings, castles, walls and towers), archaeological and vernacular (earthen architecture scattered/grouped into urban or rural nuclei) and their morphology (num. of floors, freestanding/with party walls, flat/inclined roof...)

TASK 1.5: Mapping of constructive characteristics: the database developed in task 1.3 will be used to complete the atlases drawn up in previous projects (RES-Tapia, SOS-Tierra) for constructive techniques (rammed earth, adobe, half-timber, cob) and their variants (earth, earth and lime, earth and stone, earth and brick, earth and gypsum...)

\subsection{Phase 2: identification of hazards and vulnerability study}

TASK 2.1: Identification of natural, social and anthropic hazards: a broad study will be carried out from the bibliography to produce a complete list of the hazards affecting architectural heritage and earthen architecture in particular, as well as the transformation mechanisms and dynamics stemming from these.

Among the natural hazards special attention will be paid to natural factors (wind, relative humidity, temperature, solar radiation, dust, rain, stagnant water, microorganisms...); factors linked to climate change (storms, floods, drought, desertification, change of temperatures...); unforeseen ecological and geological events (volcanic eruptions, earthquakes, landslides...). 
The social hazards include socio-economic factors (depopulation due to migration and unemployment; development of urban areas, development linked to tourism...), in addition to socio-cultural hazards (social discredit, lack of appreciation, abandonment due to changes in ways of life, etc.), and anthropic hazards (neglect, lack of maintenance, lack of protection and cataloguing...).

TASK 2.2: Identification of vulnerability factors of earthen architecture: among the vulnerability factors understood as factors of susceptibility and the factors of resilience, taking into account the factors linked to the material and constructive technique used, to the morphology of the buildings and the whole, to position and implementation, to the degree of maintenance, conservation or degradation, to the type of interventions carried out, etc.

\subsection{Phase 3: study at territorial scale}

TASK 3.1: Compilation of the thematic risk maps of the Iberian Peninsula: based on the hazards identified in task 2.1 a compilation will be carried out of all necessary maps available at Instituto Geográfico Nacional, Agencia Estatal de Meteorología, Instituto Nacional de Estadística, Instituto Geológico y Minero de España, Institut Cartogràfic i Geològic de Catalunya, Ente Vasco de Energía, Diputación General de Aragón, Instituto Geologico e Mineiro do Portugal, Laboratório Nacional de Energia e Geologia do Portugal and other public organisms in Spain and Portugal where maps showing susceptibility and/or risk of natural phenomena have been drawn up: climate factors (rainfall, temperatures, climate, solar radiation), geological factors (lithology, seismicity), social factors (population density, tourist index), seismic risk map for Spain 2015; mean number of forest fires per year; risk of forest fire; erosive states; risk of desertification; tourist index and evolution; risk of erosion; risk of floods; risk of landslides and detachments; risk of desertification of the soil, etc.

TASK 3.2: Creation of susceptibility maps for earthen architecture in the Iberian Peninsula: after completing the earthen architecture atlas with location by type, morphology and constructive technique (tasks 1.4 and 1.5) and compiling all the themed maps for hazards and risk for the Iberian Peninsula (task 2.1) these will be cross-referenced to produce maps identifying the most important processes affecting earthen architecture in the different regions and areas of the Iberian Peninsula. The overlap of different hazards and dangers (such as depopulation and floods, seismic risk and tourist concentration, etc.) and architecture found in the area will provide a first reading and analysis at a territorial scale. All the methods stated above will be used when composing the definitive danger map. This will provide the hazard model for natural and social phenomena applied to the area under study, presenting five levels or ranges: very high, high, medium, low and very low.

\subsection{Phase 4: Case Studies}

TASK 4.1: Selection of provinces, regions and/or areas under study: based on the study presented in sections 1 and 2 and the susceptibility maps developed in task 3.2 of this methodology, the specific provinces, regions or areas where a concentration of hazards or a specific hazard with a high susceptibility to the quantity and quality of earthen built heritage found in the area would be identified.
TASK 4.2: Selection of case studies in the regions selected: among the areas identified as of major interest in task 4.1 a series of representative and accessible cases of monumental (castles and towers, churches, etc.) and vernacular architecture (scattered or grouped in rural settings) will be selected, along with archaeological sites. Approximately $30-40$ cases will be selected, although the number may change depending on the needs of the study. These cases are documented with fiches on case studies with the following data: building location; general data on the building; photographic documentation of the building; constructive techniques used in the building with different constructive elements; state of degradation; occasional recent interventions...

TASK 4.3: Case studies: for each case (monumental and vernacular architecture and archaeological sites) data will be collected in situ and processed in the office from a multidisciplinary perspective to be analysed subsequently in task 4.5. Different aspects will be examined in-depth in addition to a general description of the case study. A study will be carried out on the general conditions of the building or complex; the natural and anthropic setting; climate conditions, urban regime; major social aspects; tourist development; constructive materials and techniques, economic and administrative conditions; state of degradation; and structural damage. Different tools will be used in the study: compilation of existing studies, newly composed specific fiches, photographic documentation and mapping to study them; thermography to detect damp and discontinuities...

TASK 4.4: Surveys on changes in social habits and cultural values: threats to earthen built heritage include all those related to changes in ways of life of the population and the formation of its cultural consciousness. It is essential to identify the key factors in these processes to subsequently establish lines for correction, awareness and education in favour of local cultural heritage, especially earthen. Surveys will be carried out in some case studies. The questionnaires will be distributed among the different social groups of the population involved, including administrative staff in town halls and administrations involved with traditional methods and computing tools.

TASK 4.5: Vulnerability analysis of case studies: following the data collected in tasks 4.3 and 4.4, a multi-disciplinary examination will be carried out of the susceptibility aspects (negative elements which tend to increase risk due to hazards) and resilience (positive elements which tend to mitigate risk due to hazards) such environmental, morphological material, constructive, seismic, socio-cultural, socio-economic, anthropic vulnerability, etc.

TASK 4.6: Identification of interventions for increasing the resilience of earthen architecture of the Iberian Peninsula: after the analysis of vulnerability (susceptibility and resilience) of earthen architecture and archaeological sites (task 4.5) in the case studies, a wide range of strategies will be proposed to improve resilience: protection, preventive conservation, structural consolidation, diffusion and education, awareness, training, etc. For each strategy a series of actions compatible with the different needs in the case studies (task 4.5) will be established. The possible actions will be identified through the study of national and international best practice cases identified in the literature and consultation with national and international experts, organisms and administrations. 


\subsection{Phase 5: experimentation with constructive details}

TASK 5.1: Construction of examples of rammed earth, adobe and half-timber walls: with the results of the study of earthen architecture (Phase 1 of this methodology) sample walls will be built using some of the most common techniques identified (rammed earth, lime-crusted rammed earth, lime-mixed rammed earth; adobe walls using different bonds and adobe with different compositions; half-timber with adobe and different bonds, with cob, etc.).

These samples will be built in the open air laboratory which is at the disposal of the research group in the UPV, and which is frequently used for this type of experiment. The samples will be produced controlling orientation in order to ensure adequate monitoring, and composition and execution will be controlled so that the experiment can be reproduced. Based on the results of the previous study, some particularly recurring situations of vulnerability will be simulated.

TASK 5.2: Controlled reproduction of material degradation: once the samples settle natural degradation phenomena will be reproduced in a controlled manner, including rain (with different intensities and directions until storms are simulated), damp at the base of the wall (from rising damp to the simulation of a flood), wet and dry cycles. Simulations will also be carried out of structural damage such as cracks and collapses, damage to the base of walls, etc.

TASK 5.3: Monitoring the effects of material degradation: samples of constructions for experiments will be monitored throughout the duration of the project, both simultating environmental agents and simply exposing to real climate and environmental conditions. Follow-up and monitoring will be carried out using a thermal camera to observe the evolution of damp on the wall. A meteorological station will be in operation throughout the process to measure wind speed and direction; temperature and humidity; perceived and dew point temperature; current and accumulated rain; intensity of rainfall; current atmospheric pressure and tendency.

TASK 5.4: compressive stress and wet and dry tests are carried out in the materials laboratory. while in the chemical laboratory charaterization tests will be carried out on samples of the same compositions as the wall and during the monitoring process. These analyses will provide important data on the behaviour of materials when exposed to natural phenomena.

TASK 5.5: dynamic stress tests are carried out using a vibrating table on test samples with the same compositions as the wall samples. These tests provide important data on the behaviour of constructive materials and techniques in different types of natural risk situations.

TASK 5.6: once the different simulations of decay and damage phenomena of the samples are carried out, experiments will be executed using different consolidation, conservation and repair techniques (protection of the crowning, sealing and stapling of cracks, reconstituting missing parts of wall, repair of gaps...) with different materials (lime, limewash, gypsum, earth and lime, earth and gypsum...). These tests will allow the identification of the most compatible materials and techniques for each type of wall and each case of degradation and damage.

\subsection{Phase 6: development of risk maps on different scales}

TASK 6.1: risk maps on a territorial and regional scale will be drawn based on the maps created in task 3.2, the case studies in specific areas/regions (task 4.1) and the study and analysis of both monuments, vernacular architecture, and archaeological sites (tasks 4.2 to 4.5 ).

TASK 6.2: a detailed study for risk will be carried out for individual case studies, detailing the levels of risk of each segment. These are due to the combination of hazards, danger and vulnerability of the building or complex.

TASK 6.3: risk maps on a detail scale will reflect the study of hazards and vulnerability on the scale of the construction samples experimented with. These plans will show the most vulnerable sections (corners, joints, etc.) depending on the natural and anthropic hazards.

\subsection{Phase 7: development of risk maps on different scales}

TASK 7.1: as a main result of this project guidelines will be drawn up for the design of intervention strategies and for improving the resilience of earthen architecture in the Iberian Peninsula. This guidelines will establish at least the elementary guidelines or most suitable preventive and corrective measures for improving resilience of earthen architecture in the Iberian Penisula. The document will be especially important for the institutions in charge of restoring and managing architectural and archaeological heritage as it will be a tool for the orientation of interventions in the cultural heritage of the Iberian Peninsula and can also be exported to other settings.

\subsection{Phase 8: dissemination and transfer of knowledge}

The result of the research project Risk-terra will be disseminated through different actions: the publication of articles and congress papers; the organization of a scientific seminar to share the initial development of the research with national and international experts in the field, as well as to exchange experiences that will enrich the following phase of the research; a website for the dissemination of the project results, that is is currently active (https://riskterra.blogs.upv.es/), that will be updated with the progressive outcomes of the research; the organisation, layout and production of an exhibition with the results of the research carried out in the project; etc.

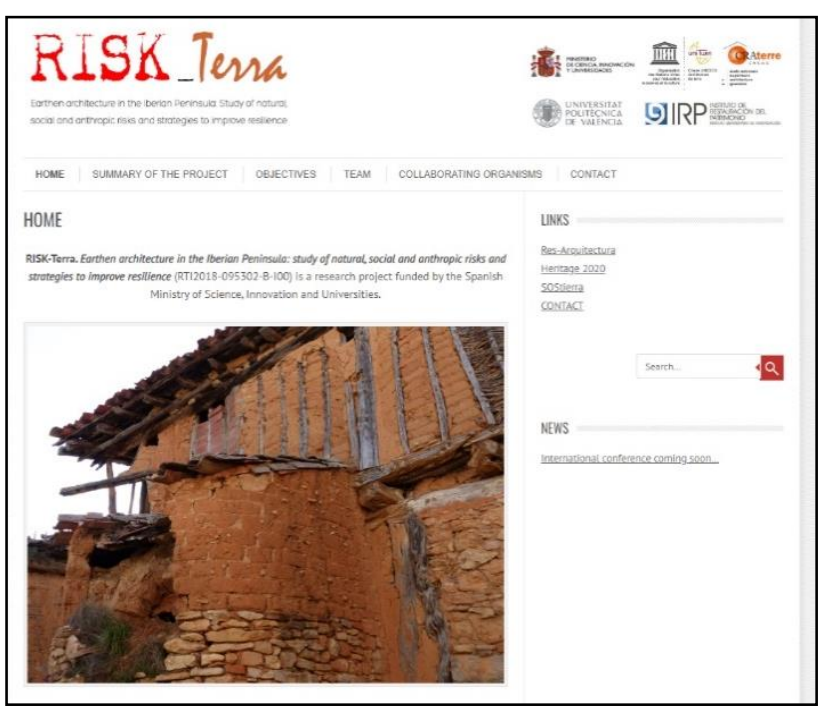

Figure 5. Risk-Terra Research Project webpage 


\section{CONCLUSIONS}

RISK-Terra research project aims to provide a scientific study of natural hazards (floods, landslides, earthquakes, winds, rise of temperatures), social hazards (abandonment, loss of social reputation, demographic pressure, tourism development...) and anthropic hazards (carelessness and negligence, lack of protection and maintenance...), as well as deterioration mechanisms (erosion, loss of materials/parts, collapse...) and transformation dynamics (replacement, use of incompatible techniques and materials...), to which the earthen architecture of the Iberian Peninsula is currently subject.

The aim of the project is to establish strategies for conservation, intervention and rehabilitation in order to prevent and mitigate possible damage through compatible actions and/or actions aimed at increasing resilience. Research is to be developed on 3 scales: territorial scale of the Peninsula; intermediate scale of regions, settlements and complexes; and detailed scale of the architecture and constructive elements. The natural, social and anthropic risks based on hazards, frequency and intensity, and vulnerability (susceptibility and resilience) of earthen architecture will be studied on these 3 scales.

Ultimately the project aims to provide guidelines relating to the risks of earthen architecture in the Iberian Peninsula in order to plan and prioritise actions to mitigate their effects with predictive, preventive and corrective measures. It also aims to transfer its results to specialists and society in general through publication, dissemination and training actions.

The methodology proposed for this research, and presented in this paper, will be applicable to other types of vernacular and monumental architecture as well as to other contexts, both in and outside Europe.

\section{ACKNOWLEDGEMENTS (OPTIONAL)}

This works is part of the research project "Earthen architecture in the Iberian Peninsula: study of natural, social and anthropic risks and strategies to improve resilience" Risk-Terra (ref. RTI2018-095302-B-I00; main researchers: Camilla Mileto y Fernando Vegas), funded by the Spanish Ministry of Science, Innovation and University.

\section{REFERENCES}

AAVV, 2014: Heritage for tomorrow. Vernacular knowledge for Sustainable Architecture, Firenze University Press

Andreatta M., Coppola F., Modelli A., Santopuoli N., Seccia L., 2017: Proposal for a new environmental risk assessment methodology in cultural heritage protection. Journal of Cultural Heritage, 22-32, 23

Gómez J., Vegas F., Mileto C., García L., 2019: Techniques and characteristics of traditional earthen masonry. The case of Spain. International Journal of Architectural Heritage. doi: $10.1080 / 15583058.2018 .1563238$

ICOMOS, 2010: Lima declaration for disaster risk management of cultural heritage. https://www.icomos.org (05/10/2019)

Mileto C., Vegas F., 2018: Earthen architecture: sustainability and heritage. Compases. The architecture and interior design international magazine / Middle East, 29, 36-42
Mileto C., Vegas F., García L., Villacampa L., Gómez J., 2019: Vernacular earthen architecture in the iberian peninsula. First phase of taxonomy and geographical distribution, Earth USA 2017. Proceedings, 102-107

Mileto C., Vegas F., Villacampa L., García L., 2019: The influence of geographical factors in traditional earthen architecture. The case of the Iberian Peninsula. Sustainability, 11/2369. doi:10.3390/su11082369

UNESCO, 2010: Glossary of basic terminology on disaster risk reduction. https://unesdoc.unesco.org (25/01/2019) 